\title{
Sacrococcygeal Teratoma in a Child: A Case Report
}

\author{
${ }^{1}$ Yam B Roka, ${ }^{2} \mathrm{M}$ Shrestha, ${ }^{3} \mathrm{~S}$ Pandey \\ ${ }^{1}$ Dr. Yam B. Roka, MBBS, M.S, M.Ch (Neurosurgery), FNNI (Skull Base Surgery), Chief of Neurosurgery, ${ }^{2}$ Dr. Manzil \\ Shrestha, MBBS, MD, Division of Anaesthesiology, ${ }^{3}$ Dr. Sagar R Pandey, MBBS, MD, Division of Pathology, Neuro \\ Hospital, Jahada Road, Biratnagar-13, Nepal.
}

Address for correspondence: Dr. Yam B Roka, E-mail: dryamroka@yahoo.com

\begin{abstract}
Sacrococcygeal teratomas (SCT) are tumors that arise in the sacrococcygeal area containing tissue from all three germ layers. SCT has an incidence of approximately one in 35,000 - 40,000 live births with malignant transformation with increasing age. We report a case in a four year old which was excised completely via the postanal route with no operative or postoperative morbidity. The histopathology was that of yolk sac variant and she is planned for chemoradiotherapy.
\end{abstract}

Key words: Childhood tumors, Sacrum, Sacrococcygeal teratoma

\section{Introduction}

$\mathrm{S}^{\mathrm{a}}$ acrococcygeal teratomas (SCT) are tumors that arise in the sacrococcygeal area containing tissue from all three germ layers. SCT has a incidence of approximately one in $35,000-40,000$ live births with malignant transformation with increasing age ${ }^{1,2}$. SCT is more common in females with a male, female ratio of 1:3-4,5. SCT may present in three categories- fetal, neonatal and children. Prenatal ultrasound can detect fetal tumors with or without maternal symptoms. Those presenting at birth are usually mature or immature teratomas. Large sacral mass that has been increasing progressively is the commonest type of presentation in children. Those presenting late have a poorer outcome than the early detected ones.

\section{Case Report}

A 4-year old girl presented with a sacral mass in the perianal area since birth. The mass had been slowly and progressive growing to reach the present size. It had also grown to the extent that she could not sleep in supine position. There was no history of altered bowel or bladder habits or weakness of the legs. On examination the child was alert, adequately built with a large solid-cystic mass of $20 \times 25 \mathrm{~cm}$ in the sacrum with the anus grossly pushed anteriorly (Fig. 1). No weakness of the lower limbs or intrabdominal mass was palpable. The ultrasound of the abdomen did not reveal any genitourinary abnormality. Magnetic Resonance Imaging (MRI) revealed a large heterogeneous mass arising from the sacrococcygeal area with the rectum pushed anteriorly (Fig. 2). There was no spinal dysraphism.

Preoperatively she was planned with full bowel preparation and consent for possible colostomy. She underwent complete excision of the mass by the postanal route along with the lower sacrum with no intraoperative or postoperative problems (Fig. 3). Intraoperatively there was no infiltration into the pelvic structures. The sutures were removed on the $10^{\text {th }}$ day and she was discharged (Fig. 4). There was no postoperatively bowel or bladder incontinence. Histopathology revealed the tumor showing mature dermal components of stratified squamous epithelial lining with hair follicles, mature adipose tissue, gastric and respiratory epithelium and yolk sac component (Schiller-Duval bodies) suggestive of mixed malignant SCT (Fig. 5). The tumor was positive for alfa fetoprotein on immunohistochemistry. She has been planned for further chemoradiotherapy. 


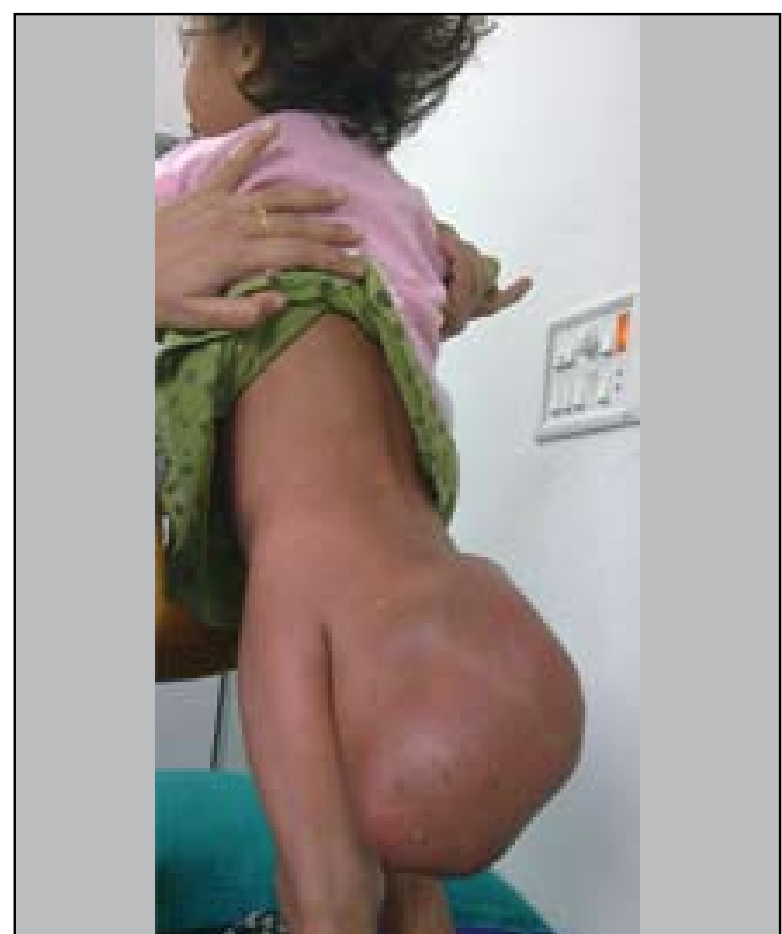

Fig. 1: Preoperative picture of the patient showing the large sacral tumor.

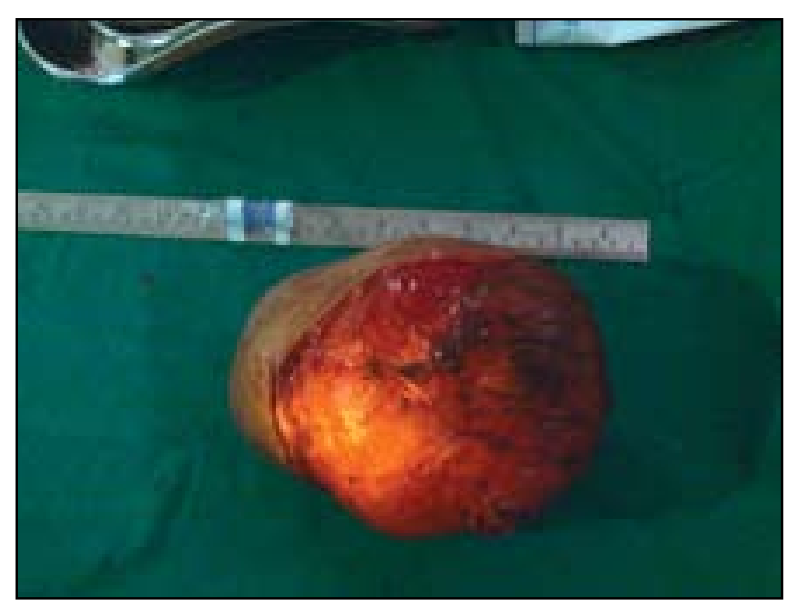

Fig 3: The excised tumor weighing 2 kilograms.

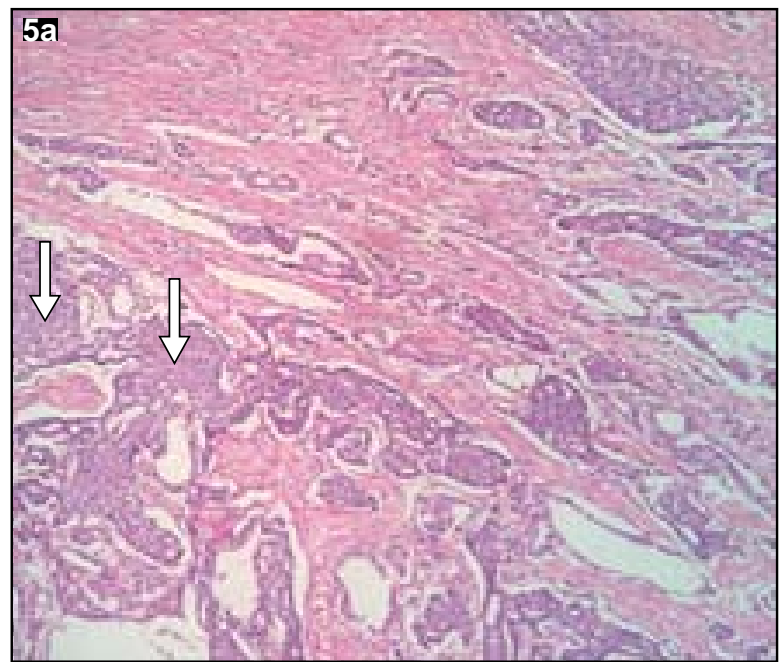

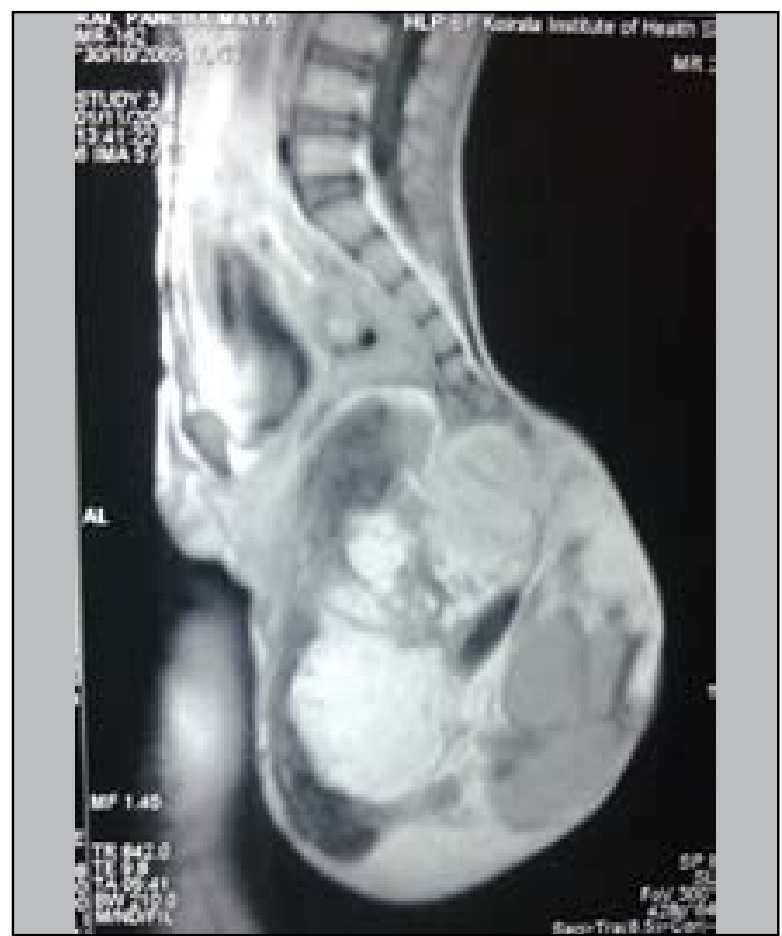

Fig 2: MRI showing the heterogenous mass arising from the coccyx and pushing the rectum anteriorly.

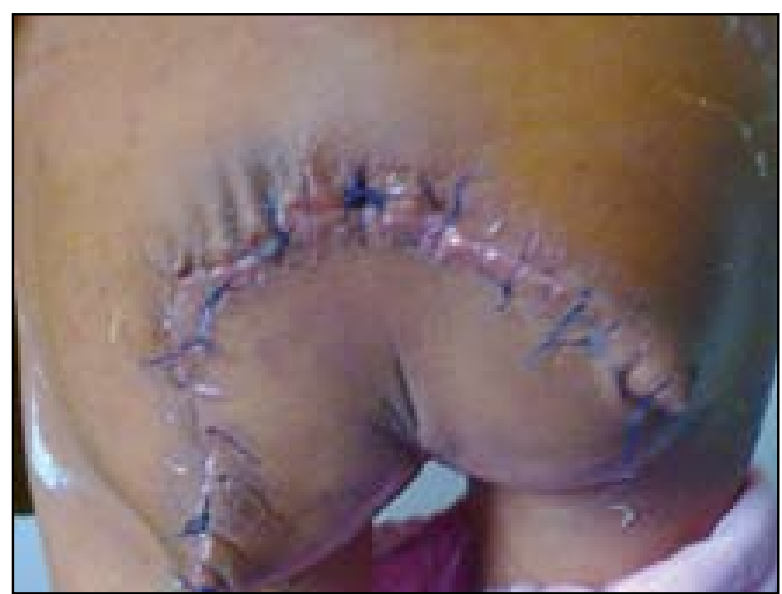

Fig 4: Postoperative picture at 10 days showing complete excision of tumor.

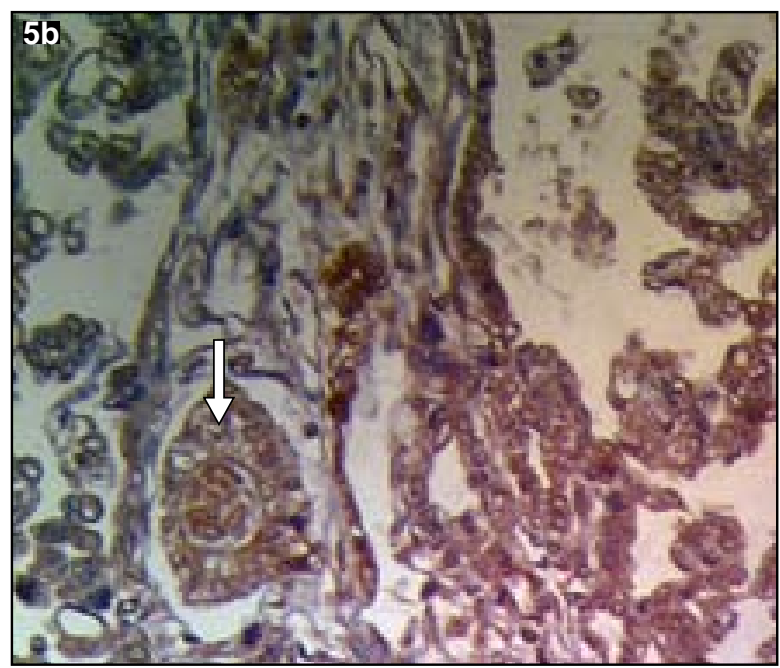

Fig 5a \& b: Histopathology (H\&E stain) showing yolk sac components and Schiller-Duval bodies. 


\section{Discussion}

SCT are tumors that arise in the sacrococcygeal area containing tissue from all three germ layers. SCT has a incidence of approximately one in 35,000 - 40,000 live births with malignant transformation with increasing age $\mathrm{e}^{1,2}$. SCT is more common in females with a male, female ratio of $1: 3-4^{3,5}$. These tumors are thought to arise in the Hensons node which contains pleuripotent cells and may present prenatally, at birth or later in life ${ }^{6,7}$. Antenatal detection of SCT by use of three-dimensional (3D) sonography has a worse outcome than those diagnosed after birth with survival rates ranging from $54-77 \% \%^{7,8,9}$. Large tumors detected antenatally or those with excess amniotic fluid then early caesarean section must be planned. These tumors may present with varying symptoms like bowel or bladder incontinence, backache, weakness of limbs or fistula of the urogenital or gastrointestinal tracts. MRI shows the tumors relation with the adjacent organs with infiltration suggesting malignant transformation. Other congenital anomalies like defects in the cloacal and hindgut are associated in $10-24 \%$ of cases $^{10}$. Complete excision including the coccyx and sparing the sacral nerves leads to low recurrence. The recurrence is high in the first three years after surgery and therefore needs regular followup ${ }^{11}$. Those tumors with malignant changes need further chemoradiotherapy.

\section{References}

1. Pantanowitz L, Jamieson T, Beavon I. Pathology of sacrococcygeal teratomas. S Afr J Surg 2001; 39:56-62.

2. Flake AW. Foetal sacrococcygeal teratoma. Semin Pediatr Surg 1993;2:113-120.

3. Gatcombe HG, Assikis V, Kooby D, Johnstone PA. Primary retroperitoneal teratomas: a review of the literature. J Surg Oncol 2004;86:107-113.
4. Altman RP, Randolph JG, Lilly JR. Sacrococcygeal teratoma: American Academy of Pediatrics Surgical Section Survey-1973. J Pediatr Surg 1974; 9:389-398.

5. Keslar PJ, Buck JL, Suarez ES. Germ cell tumours of the sacrococcygeal region: radiologic-pathologic correlation. Radiographics 1994;14:607-620.

6. Roka YB, Koirala R, Bajracharya A, Shah S, Khaniya S. Giant sacrococcygeal teratoma in an adult: case report. Br J Neurosurg 2009;23:628-9.

7. Roman AS, MonteagudoA, Timor-tritsch I, Rebarber A. First-trimester diagnosis of sacrococcygeal teratoma: the role of three-dimensional ultrasound. Ultrasound Obstet Gynecol 2004; 23:612-614.

8. Hedrick HL, Flake AW, Crombleholme TM, et al. Sacrococcygeal teratoma: prenatal assessment, fetal intervention, and outcome. J Pediatr Surg 2004;39:430-8.

9. Makin EC, Hyett J, Ade-Ajayi N, Patel S, Nicolaides $\mathrm{K}$, Davenport M. Outcome of antenatally diagnosed sacrococcygealteratomas:single-centerexperience (1993-2004). J Pediatr Surg 2006;41:388-93.

10. Gabra HO, Jesudason EC, McDowell HP, Pizer BL, Losty PD. Sacrococcygeal teratoma--a 25-year experience in a UK regional center. $J$ Pediatr Surg 2006;41:1513-6.

11. Zaccara A, lacobelli BD, Adorisio O, Petrarca M, Di Rosa G, Pierro MM, Bagolan P. Gait analysis in patients operated on for sacrococcygeal teratoma. J Pediatr Surg 2004;39:947-952. 